\title{
MERSBE - mercado de ruídos e sons para o bem-estar: modulações da escuta e cultura aural contemporânea
}

\author{
Vinícius Andrade Pereira \\ Universidade do Estado do Rio de Janeiro, Faculdade de \\ Comunicação Social, Rio de Janeiro, RJ, Brasil \\ ORCID: http://orcid.org/0000-0003-3593-2521
}

\section{Resumo}

O presente artigo explora um mercado sonoro único: o MERSBE - Mercado de Ruídos e Sons para o Bem-Estar. Tal mercado se caracteriza por apresentar propostas ruidosas com fins diversos, tais como o aprimoramento da memória e da qualidade do sono, aumento da capacidade de concentração, curas físicas e psíquicas, dentre outras, sempre comprometidas com o bemestar. A emergência do MERSBE revela, ainda, como a cultura contemporânea estabelece novos modos de se relacionar com os ruídos, invertendo o que parecia ser a lógica dos seus usos até há pouco tempo. De uma posição provocadora e contestatória - como no caso do Manifesto Futurista de Russolo, na música concreta, ou ainda em músicos como E. Varese e J. Cage, até o movimento punk e o noise japonês - os ruídos parecem, agora, servir a mercados globais, sendo acolhidos e cultivados como experiências positivas e dóceis. Como isso pode afetar a cultura aural contemporânea? Essa é a questão central desse artigo, que foi elaborado a partir de uma imersão em sites de redes sociais, como o Youtube, para a observação dos produtos sônicos analisados. Como referência teórica principal estão os Estudos de Som e autores que trabalham com as materialidades da comunicação, principalmente. Como resultados finais, o artigo aponta alguns fatores que já podem ser entrevistos como partícipes relevantes, na modulação da escuta de ruídos na cultura aural contemporânea.

\section{Palavras-chave}

MERSBE. Ruído. Bem-Estar. Cultura Aural.

\section{Introdução}

Uma ovelha de pelúcia, bege, de cerca de $20 \mathrm{~cm}$, é vendida no mercado de produtos para bebês com uma proposta singular: para além do objeto lúdico e decorativo que é, traz 
embutido no seu corpo um pequeno sistema de som, composto de micro autofalantes, botã o liga/desliga e volume, além de quatro outros botões que, acionados, reproduzem diferentes ambiências sonoras que evocam sons de baleias se comunicando, da chuva, das ondas do mar e de um amanhecer na mata (com pássaros cantando e um murmurar de riacho). Há ainda um botão com o qual se pode controlar o tempo desejado de duração da trilha sonora - 25 ou 45 minutos. A ovelhinha - encontrada em lojas online com o nome de Sleep Sheep ${ }^{1}$ traz também duas tiras em velcro na parte superior do seu corpo, de modo que possa ser presa na parte externa de um berço e, uma vez ligada, revela seu propósito principal: induzir e manter a qualidade do sono do bebê.

Uma busca rápida no Google ou no Youtube permite constatar que a ovelha não está sozinha. Junto com tigrinhos, corujinhas, tartaruguinhas, ursinhos, dentre outros bichinhos, faz parte de um mercado que propõe os mais variados tipos de ruídos e sons para garantir a qualidade do sono dos bebês.

Mergulhando mais fundo nesse universo, encontra-se uma infinidade de ofertas de produtos sonoros que se voltam para a promoção do bem-estar ${ }^{2}$, indo muito além da qualidade do sono e do universo infantil. Há prescrições auditivas para o aprimoramento da memória, da concentração, da criatividade, para o relaxamento físico e mental, para a liberação de endorfina, dopamina e serotonina - consideradas "hormônios da felicidade" -, para melhorar o aprendizado ou o sistema imunodepressor, para se ter "orgasmos cerebrais", para curar corpo e mente, dentre outros tantos fins, sempre comprometidos com o bem-estar pessoal.

Considerando a quantidade de produtos ofertados -na ordem de dezenas de milhões apenas em um site de compartilhamento de vídeos como o Youtube - pode-se afirmar que uma nova classe de commodity sonora aflora na cultura aural contemporânea. Agora, para além da música, das trilhas sonoras e do design de som para audiovisuais e games, das marcas sonoras (sound branding), de vinhetas, de jingles e de toda uma sorte de ruídos e sons partícipes dos códigos sonoros que regulam relações entre humanos, aparelhos e máquinas variadas, ruídos e sons singulares emergem com novos significados e valores.

0 presente artigo toma como objeto de investigação o conjunto de ofertas sonoras voltado para o bem-estar, mencionado brevemente, nomeando-o com a sigla MERSBE -

\footnotetext{
${ }^{1} 0$ nome é uma brincadeira com a rima das palavras inglesas sleep (to sleep = dormir) e sheep (ovelha) e a função à qual se propõe o objeto - ajudar na qualidade do sono dos bebês.

20 conceito de bem-estar é discutido mais à frente. Por ora, pode-se entendê-lo como um conjunto de realizações relacionadas à saúde, à virtude e ao prazer.
} 
Mercado de Ruídos e Sons para o Bem-Estar. ${ }^{3}$ Aposta-se que uma compreensão melhor das peças, atores e dinâmicas que compõem esse mercado pode revelar possíveis modulações da escuta em processo, particularmente em relação aos ruídos, assim como aspectos novos da cultura aural contemporânea.

\section{Objetivos}

0 artigo explora, como afirmado, o que a emergência de um mercado sonoro como o MERSBE pode revelar sobre processos de modulações de escutas na contemporaneidade, quando produtos sônicos ruidosos parecem ser revalorizados. Com isso, espera-se, ainda, compreender possíveis transformações que ocorrem na própria cultura aural hodierna. Os objetivos específicos do artigo são:

a) realizar uma apresentação exploratória do MERSBE, trazendo à tona alguns de seus atores, produtos, propostas e mensagens promocionais;

b) articular ponderações e reflexões em torno dos processos e experiências de escuta que estariam implicados com a emergência desse mercado e a revalorização de produtos sonoros ruidosos, bem como sobre a cultura aural contemporânea;

c) apresentar, ao final, questões e encaminhamentos que atuarão como apontamentos e norte para outros estudos, desdobramentos e diálogos sobre o tema.

\footnotetext{
${ }^{3}$ A proposta do nome MERSBE se afirma como um conjunto de movimentos e sentidos que implicam um dos temas centrais do presente estudo, de estudos anteriores e, também, de performances artísticas do autor: o ruído. Em primeiro lugar, reúne, na forma de um acrônimo, os elementos em foco do estudo: mercado, ruídos, sons e bem-estar. Em segundo lugar, presta uma homenagem, pela proximidade fonética, ao artista Merzbow (Masami Akita), um dos expoentes do movimento noise japonês. Ainda, por trazer uma certa dificuldade ao falante nato de português, a palavra MERSBE, ao ser pronunciada, especialmente pelo encontro das consoantes "r", "s" e "b", acaba por gerar certo desconforto e ruído. Por fim, também pela sonoridade, ao evocar uma proximidade com a palavra "merda", produz-se, mais uma vez, uma espécie de ruído, ainda que de natureza semântica. Em todos esses movimentos e sentidos, pode-se entreouvir ruídos.
} 


\section{MERSBE - Mercado de Ruídos e Sons para o Bem-Estar}

Um dos primeiros cuidados que se quer ter ao explorar o novo mercado sonoro apresentado é trazer mais clareza para três dos termos que participam na sua nomeação, a saber: sons, ruídos e bem-estar. Tal cuidado se mostraria inócuo, uma vez que há ambiguidades na forma como os termos "som" e "ruído" são usados pelo mercado em questão. Ou seja, há ofertas de produtos sonoros que se apresentam como sons, quando tecnicamente seriam ruídos e vice-versa. Se para a exploração empreendida, demarcar claramente as fronteiras entre som e ruído não parece rentável, isso pode ser diferente quando se considera uma perspectiva histórica mais ampla sobre esses termos, em busca de uma melhor compreensão sobre possíveis modulações da escuta, particularmente no que diz respeito aos ruídos na contemporaneidade. O termo "bem-estar", por outro lado, historicamente não se vincula às investigações sobre sons e música, o que demanda cuidado particular ao utilizá-lo dentro desse campo.

\subsection{Sons}

Como considerado em outro momento, em diálogo com o trabalho de Sterne (2003):

A ideia de som enquanto categoria autônoma de estudos surge tardiamente entre o século XVIII e o ínicio do século XX, evidenciando-se a partir dos estudos destinados ao mapeamento da física das ondas sonoras e da audição enquanto processo fisiológico (PEREIRA; CASTANHEIRA; SARPA, 2010).

Uma definição técnica de som - conceito que não varia muito entre manuais de acústica ou física - irá afirmar que se trata de um fenômeno que se entende como uma propagação longitudinal e circuncêntrica de uma onda mecânica, através de meios materiais (que têm massa e elasticidade) como os sólidos, líquidos ou gasosos. Um som "puro" , isto é, com apenas um tom, é representado por uma senoide que se caracteriza por movimentos oscilatórios regulares, cuja frequência pode ser avaliada pela unidade de medida hertz (Hz) e de uma amplitude (energia ou volume) que se avalia por meio da unidade de medida decibel (dB). Para além de uma definição técnica, para se compreender plenamente como uma onda física se apresenta como uma expressão sonora ao se propagar, e ainda como os sons são percebidos e qualificados, seria necessário recuperar proposições neurológicas e psicoacústicas acerca do funcionamento da audição e de como a escuta é influenciada por 
dinâmicas sociais e técnicas (STERNE, 2003). Tarefa complexa, que permite múltiplas abordagens e que será reencaminhada oportunamente.

No caso do MERSBE, o termo "som" é apresentado apenas por uma questão de rigor conceitual, uma vez que, entre o conjunto de produtos sonoros que são oferecidos, tecnicamente não se encontra apenas ruídos, mas também sons, como os binaurais, por exemplo, e até mesmo músicas - ainda que voltadas para fins específicos relacionadas ao bem-estar e, assim, preparadas para atuarem de determinado modo junto às mentes e corpos dos seus ouvintes, como será mostrado.

\subsection{Ruídos}

A ideia de ruído marca-se pela equivocidade já desde suas primeiras acepções, como aponta Murray Schafer, quando o define como "som não desejado", observando que tal definição já estaria presente no The English Oxford Dictionary em 1225 (SCHAFER, 2001). Tal compreensão cobre o termo de um caráter subjetivo, que obriga o estudioso a considerar modulações valorativas em relação ao ruído em diferentes períodos históricos e contextos culturais (SCHAFER, 2001, p. 367). Assim, uma definição técnica de ruído pode servir para superar a equivocidade da definição apresentada para os objetivos de discernir minimamente sobre a variedade de produtos do MERSBE. Registra-se, dessa forma, uma compreensão técnica de ruído como expressões audíveis cujas ondas vibratórias se apresentam de modo aperiódico. Para a Teoria Acústica, o ruído, como um conjunto de vibrações com periodicidades erráticas, não permite que se detecte suas frequências auditivamente de modo mais apurado. Nesse sentido, o ruído branco, do qual se tratará à frente, se apresenta como modelo exemplar (PEREIRA;CASTANHEIRA; SARPA, 2010).

Para o estudo do MERSBE, interessarão ruídos que, alegadamente, trabalhariam no aprimoramento de alguma faculdade psíquica, comportamento ou aspecto da saúde, assim como aqueles que se relacionam com sensações de prazer, sempre voltados para o bemestar. Como se observará, há produtos ruidosos distintos que serão objetos de consideração e reflexão.

\subsection{Bem-Estar}

A história do conceito de bem-estar se confunde com a própria história da filosofia, particularmente quando conjugada à luz do termo grego eudaimonia ("eu" = "bom" e 
"daimon" = "gênio" ou "espírito") que pode ser entendido, genericamente, como sinônimo de felicidade. Como tal, aparece como um dos conceitos centrais na obra Ética a Nicômaco, de Aristóteles (2013), como o estado que se pode alcançar com a realização plena da virtude.

Uma outra perspectiva que se coloca para a conquista da eudaimonia seria a de evitar a dor e vivenciar prazeres, perspectiva que encontra em Aristipo de Cirene, filósofo grego que viveu por volta de 400 a.C., um de seus expoentes. Para o filósofo, a felicidade seria o somatório do maior número de momentos prazerosos vividos, fundando, assim, o bem-estar e a felicidade no hedonismo (BIANCHI; SCALABRIN; PENTERICH, 2006).

O bem-estar como objeto de estudo científico, contudo, situa-se a partir da segunda metade do século XX, ganhando mais força a partir da década de 1990, especialmente com a Psicologia Positiva, a partir de estudos que buscavam uma abordagem científica acerca da felicidade. Esse enfoque teórico é concebido como o estudo científico das forças e virtudes próprias do indivíduo, investigando sentimentos, emoções e comportamentos positivos, que têm como objetivo final promover a felicidade humana (SCORSOLINI-COMIN; SANTOS, 2010).

Procura-se, assim, distinguir a ideia de um bem-estar objetivo (welfare) relacionado à garantia de instâncias materiais e sociais básicas como alimentação, educação, segurança, renda, saúde, mobilidade urbana etc. e um bem-estar individual, ou subjetivo (well-being), diretamente ligado a como o indivíduo avalia a sua qualidade de vida. Nesse sentido, usa-se com frequência a denominação bem-estar subjetivo (BES) que, por sua vez, fica fortemente vinculado às ideias de felicidade e satisfação. Estudos de revisão de literatura sobre o tema apontam para uma tendência a se vincular o bem-estar subjetivo à promoção da saúde (SCORSOLINI-COMIN; SANTOS, 2010).

Considerando os pontos expostos, em relação ao estudo sobre o MERSBE, a ideia de bem-estar se situa em uma relação direta com o tema da promoção da saúde, mas, por outro lado, acolherá a perspectiva filosófica, tanto na sua vertente hedonista, quanto na que valoriza o desenvolvimento das virtudes. Assim, compreende-se o bem-estar como práticas que visam a, por um lado, promover a saúde - quer física, quer psíquica - e, por outro, a promover faculdades relacionadas ao desenvolvimento de potenciais que poderiam ser considerados como virtudes na contemporaneidade, como a produtividade, o controle emocional ou a resiliência, mas que também possam promover experiências prazerosas, como o sono, o relaxamento e a liberação de hormônios como endorfina, dopamina e serotonina, promotoras de sensações de satisfação e de felicidade. Em síntese, para efeitos 
dos estudos sobre o MERSBE, a ideia de bem-estar se vincula ao trinômio saúde, virtude e prazer.

\section{Produtos Sonoros ofertados pelo MERSBE}

O conjunto de produtos sonoros oferecido pelo MERSBE engloba ruídos e sons voltados para o bem-estar, como afirmado. Contudo, há especificidades e particularidades que precisam ser apreciadas com mais atenção.

\subsection{Ruídos coloridos}

A respeito dos ruídos, uma primeira exploração permite observar que há um grande conjunto de ofertas que se apresenta na forma de "ruídos coloridos" - ruído branco (white noise), ruído rosa (pink noise) e ruído marrom (brown noise), principalmente. 0 ruído branco, como mencionado acima, consiste em um grande conjunto de frequências sonoras com periodicidades aleatórias sobrepostas, o que lhe dá uma densidade espectral de potência constante. Sua nomeação faz alusão à cor branca, que reuniria em si os espectros de todas as outras cores. Modulações nas frequências do ruído branco, por meio de filtros específicos, por exemplo, produziriam outras "cores" de ruídos, como o rosa, o marrom, o azul e o violeta.

Esses tipos de ruídos comparecem no MERSBE como soluções para garantir uma boa noite de sono, mas também para suavizar ou cancelar o incômodo causado por sons ou ruídos não desejados, como conversas, música, aparelhos de TV ligados, entre outros. São oferecidos também como forma de atenuar desconfortos causados pelo tinnitus ou tinido (popularmente conhecido como "zumbido no ouvido"). Há uma série de ruídos anunciados como "brancos" que são gerados a partir do que seria a reprodução do funcionamento de aparelhos e máquinas diversas, como ventiladores, aparelhos de ar condicionado, secadores de cabelo, aspiradores de pó e, até mesmo, turbinas de avião para os mesmos fins - como uma espécie de parede ruidosa mascarando outros ruídos e/ou sons.

Encontram-se, ainda, propostas de usos de "ruídos coloridos" para potencializar a concentração e o foco no desenvolvimento de atividades como o estudo ou o trabalho, entre outros fins relacionados ao bem-estar. 


\subsection{Sons e ruídos da natureza}

Há uma infinidade de produtos que simulam sons e ruídos da natureza, como sonoridades de riachos, ondas do mar, chuva, vento, cantos de pássaros, cetáceos se comunicando, animais etc. Seus benefícios, em geral, estão relacionados ao relaxamento, à indução e manutenção do sono e a "harmonizações" da mente. Trata-se de um grupo singular de sons e ruídos que existe desde sempre na história da humanidade. A novidade seria a forma de consumo e fruição desse material sonoro na contemporaneidade: coletados e escutados através de tecnologias midiáticas e não apenas diretamente em espaços ao ar livre, meios rurais, em florestas e ambientes afins.

\subsection{Sons binaurais}

Uma classe particular de sons merece atenção, pela popularidade que ganharam certamente pela alegação de respaldo científico para os fins aos quais se propõem. Trata-se dos sons binaurais e, mais especificamente, das batidas ou frequências binaurais (binaural beat).

Como o nome binaural indica, trata-se de sons que se relacionam com os dois ouvidos. São produzidos a partir de um processo de gravação conhecido como dummy head recording (gravação com cabeça falsa/de manequim), no qual dois microfones situam-se na altura dos dois ouvidos, que pode ser um manequim ou um objeto qualquer que mantenha as compleições físicas de um rosto humano. Hoje há empresas do ramo que já oferecem um sistema de gravação na forma de cabeça. Com isso, simula-se um modelo que seria a escuta "natural" humana, capaz de distinguir fontes sonoras, suas distâncias e seus movimentos, profundidades, enfim, uma experiência de "escuta tridimensional", desde que realizada com o uso de um fone de ouvidos estéreo.

$\mathrm{Na}$ verdade, a gravação de sons no modelo binaural não ganhará um realismo tridimensional tão acurado e realista se não houver o tratamento desse material sonoro por um algoritmo conhecido como Cetera. É esse algoritmo que está por trás de peças sonoras que oferecem uma forte ilusão de escuta não mediada tecnologicamente, propiciando ao ouvinte uma percepção nítida de distâncias e posicionamentos das fontes sonoras ao seu entorno, como no caso que popularizou essa experiência chamado Virtual Barber Shop, desenvolvido originalmente em 1996 pela empresa QSoundLabs 


\subsection{Batidas binaurais e tons isocrônicos}

A história das batidas binaurais é creditada originalmente ao físico alemão Heinrich Wilhelm Dove que, em 1839, descobriu que quando dois sons em frequências próximas são apresentados, cada um a um ouvido, o cérebro produziria uma terceira frequência que seria a diferença entre as frequências dos sons escutados. Assim, por exemplo, se um som de $200 \mathrm{~Hz}$ e um de $205 \mathrm{~Hz}$ se apresentam ao mesmo tempo - sempre observando que seja cada um dos sons em um dos ouvidos, ou seja, uma frequência no ouvido direito e a outra no esquerdo -, o som que se irá "escutar" terá a frequência de $5 \mathrm{~Hz}$, que é a diferença das frequências dos dois sons apresentados aos dois ouvidos.

Um grande público começa a se interessar pelas frequências binaurais com a publicidade dada ao artigo Auditory Beats in the Brain, de Gerald Oster, publicado em 1973 na Scientific American. É a partir desse artigo que especulações em torno da hipótese de o cérebro poder ter sua pulsação (ondas cerebrais) ritmada pelas batidas binaurais ganham popularidade. A ideia, então, é que experimentando sons cujas frequências binaurais resultem em uma frequência baixa - de 4 até $100 \mathrm{~Hz}$, aproximadamente - seja possível ritmar as ondas cerebrais, a fim de atingir estados cerebrais variados - Delta $(0,1-4 \mathrm{~Hz})$, Theta $(4-8 \mathrm{~Hz})$, Alpha $(8-14 \mathrm{~Hz})$, Beta $(14-30 \mathrm{~Hz})$ e Gamma $(30-100 \mathrm{~Hz}) .0$ objetivo, com isso, seria experimentar benefícios múltiplos, condizentes com cada faixa de frequência das ondas cerebrais, tais como relaxamento, foco, memória, aprendizado, energia, criatividade, qualidade do sono, alívio para males como estresse, ansiedade, dores, tinido, transtorno do déficit da atenção e hiperatividade etc. É curioso observar que toda essa especulação em torno das alterações das ondas cerebrais não se encontra no artigo original de Oster, que tinha como objetivo investigar o uso da percepção das batidas binaurais como ferramenta de diagnóstico médico (OSTER, 1973).

Os tons isocrônicos seriam uma espécie de variação das batidas binaurais e ofertados dentro do MERSBE para os mesmos fins. Trata-se de um som composto de um tom apenas - e não dois, como no caso do binaural - que pulsa em intervalos de tempos regulares. As frequências do tom isocrônico a serem usadas devem obedecer às frequências do estado cerebral que se queira atingir. Alguns adeptos defendem essa modalidade de sons como mais efetiva para alterar ondas cerebrais e ainda teria a vantagem de não precisar usar fones de ouvidos, uma vez que se trata de um som apenas. 


\subsection{ASMR - Autonomus Sensory Meridian Response}

Um outro conjunto de ruídos que é decorrente de aplicações das tecnologias de gravações binaurais é aquele que se forma em torno das práticas de ASMR - Autonomus Sensory Meridian Response. Trata-se de uma infinidade de ruídos cujo propósito seria provocar uma reação corporal que se manifesta através de formigamentos da cabeça ou das extremidades dos membros, e/ou sensação de relaxamento ou sono. Alguns adeptos de ASMR referem-se a essas sensações, particularmente o formigamento na cabeça, como "orgasmos cerebrais". Esses produtos sonoros são ofertados na forma de vídeos por pessoas conhecidas pela alcunha ASMRtists.

Os ruídos são apresentados como gatilhos (triggers) que disparam as sensações do tipo ASMR e abrangem uma variedade enorme de produtos sonoros, como sussurros, percussão de unhas sobre os mais variados objetos e superfícies, ruídos de mastigação ou de ações triviais e domésticas como preparar uma comida e folhear um livro; assopros; beijos; sons feitos com as mãos ou com a boca, como estalar de línguas ou abrir e fechar a boca; barulhos produzidos ao esfregar objetos de diferentes materiais nos microfones, como hastes flexíveis, pentes, esponjas, plásticos, entre uma infinidade de outros modos de produção de ruídos voltados para promover experiências agradáveis como o sono e, em geral, o bem-estar.

Vale ressaltar que o ASMR enquanto cultura sonora é um fenômeno, catapultando anônimos ao estrelato. No YouTube, alguns ASMRtists arrebatam milhões de views, followers e likes com os seus produtos. Canais como o ASMR Darling, com mais de 1,4 milhão de assinantes, o Gentle Whispering ASMR, com cerca de 1,2 milhão e o PPOMO ASMR, com cerca de 1 milhão, confirmam a avidez do público por esses produtos. No Brasil, o movimento parece ir pelo mesmo caminho, ganhando mais adeptos dia a dia, quando um canal no YouTube como o Sweet Carol já conta com cerca de meio milhão de assinantes, com alguns vídeos assistidos por quase 2 milhões de pessoas.

É importante observar que os produtos ASMR incorporam, além de sons/ruídos, imagens de vídeo. Contudo, o interesse por esse movimento se justifica, como apresentado no presente estudo, pelo protagonismo que os ruídos ganham e, ainda, pela natureza do material sonoro apresentado: bizarro, incomum, dentro do que se reconhece como produtos sonoros na cultura aural até então, e sempre buscando dar uma feição agradável e doce aos ruídos. 


\subsection{Drogas digitais/sonoras}

A proposta das batidas binaurais como meio para a alteração das frequências das ondas cerebrais é a base, ainda, das chamadas drogas digitais. A ideia seria simples: a partir do mapeamento dos estados alterados de consciência produzidos por entorpecentes convencionais, a proposta das drogas digitais seria alterar as ondas do cérebro do mesmo modo, através de batidas binaurais, a fim de que os diferentes tipos de efeitos possam ser alcançados. Tal proposta baseia-se no princípio de que todas as atividades cérebroneuronais são eletroquímicas e, portanto, podem ser alteradas por via química - o caso dos alucinógenos convencionais - ou através de impulsos elétricos - o caso das drogas digitais/sonoras.

Vale observar que, tanto no caso dos benefícios propostos pelas batidas binaurais e sons isocrônicos para alteração dos estados cerebrais quanto no caso das drogas digitais, a maioria dos produtos apresenta-se como músicas. Ou seja: as batidas binaurais seriam incorporadas como sons e ritmos em certas músicas e, assim, se experimentaria o benefício de uma faixa de onda cerebral específica ou os efeitos de certa droga. Isso coloca o produto sonoro "música" como parte do conjunto sônico do MERSBE considerando, contudo, que se trata de um uso bem específico - a música como meio capaz de portar as batidas binaurais como parte da sua composição ${ }^{4}$.

Faz-se necessário, ainda, observar que, para os casos das batidas binaurais, os produtos devem sempre ser escutados através de fones de ouvido, sem os quais os efeitos da proposta não se realizariam, exatamente pelo direcionamento de sons específicos necessário a cada um dos ouvidos - e isso garantiria um processo de escuta que se daria "dentro" do cérebro.

\section{MERSBE e algumas implicações nas modulações das experiências de escuta dos ruídos e na cultura aural contemporânea}

A emergência do MERSBE evidencia um mercado robusto e vastíssimo de produtos sonoros ruidosos, o que demanda uma melhor compreensão das modulações da experiência de escuta que possam estar em processo. Explorações para tal compreensão implicam em

\footnotetext{
${ }^{4}$ É importante ressaltar que a ideia da música como meio se apresenta no trabalho de Tia DeNora, mas em uma outra perspectiva. No caso, como mediadora de estados emocionais, rítmicos, de representações de si (self), dentre outros (DE NORA, 2000).
} 
reconsiderar os modos com os quais as sociedades urbanas lidaram com os ruídos, em um recorte histórico suficientemente amplo para abarcar e comparar diferentes experiências.

Movimentos em relação aos ruídos, em pouco mais de um século, oscilam ora acolhendo-os, inscrevendo-os dentro de códigos sonoros particulares, ora rejeitando-os, proscrevendo-os, considerando-os maléficos e prejudiciais à saúde, especialmente à saúde mental. Tais oscilações - que quase sempre ocorrem em paralelo dentro de uma mesma cultura -, revelam-se a partir de acontecimentos e movimentos culturais díspares que colaboram na modulação de experiência auditivas a partir da virada dos séculos XIX e XX até o presente momento. Trata-se de uma história vasta e complexa, com atores diversos, ainda que o foco da investigação restrinja-se a correntes que afirmaram e positivaram os ruídos, movimentos mais raros e espaçados. Ainda assim, uma complexa e extensa história precisaria ser retomada, desde empresas que propuseram uma sorte de objetos e equipamentos que exigiam escutas singulares, como o caso do estetoscópio, do rádio e do telefone (STERNE, 2003), por exemplo, passando pelo Futurismo Italiano, particularmente o manifesto proposto por Russolo (2009), além de outras iniciativas singulares no campo da música, como a obra Ionisation, de Edgard Varese, o movimento da música concreta, incontáveis peças musicais de John Cage, até bandas, artistas e movimentos experimentais contemporâneos como o circuit bending ou o noise japonês, culminando na emergência do MERSBE nos dias atuais (FORD, 1999; HEGARTY, 2007; PEREIRA, CASTANHEIRA e SARPA, 2010; NOVAK, 2013) 5

Cada acontecimento ou movimento cultural mencionado oferece planos de exploração de uma história das modulações de experiências de escuta, assim como significados e usos que os ruídos ganham em cada contexto sócio-cultural.

Explorar diferentes nuances da história da revalorização dos ruídos, da modernidade à contemporaneidade, é parte dos desdobramentos que o presente estudo sugere. A empreitada é extensa demais para ser apresentada dentro do presente texto ${ }^{6}$. Contudo, alguns atores e acontecimentos implicados nesse processo de modulação da escuta na contemporaneidade já podem ser entrevistos e entreouvidos. A seguir, apresenta-se

\footnotetext{
5 Parte dessa exploração, especialmente aquela que diz respeito a movimentos dentro da história da música, foi realizada em estudos anteriores (PEREIRA; CASTANHEIRA; SARPA, 2003; PEREIRA; CASTANHEIRA, 2011).

${ }^{6}$ Uma revisão mais ampla da história dos ruídos, para além do campo da música, em diálogo com o campo dos Estudos de Som e das Teorias das Materialidades, faz parte da pesquisa intitulada "Espaço Acústico e Comunicação: Mapeamento de Códigos Sonoros nas Tecnologias Midiáticas e na Cultura Contemporâneas", que está em desenvolvimento no PPGC-UERJ, sob coordenação do autor.
} 
alguns deles, assim como algumas questões e problematizações rentáveis para os objetivos do artigo.

\subsection{MERSBE e discurso científico}

Um elemento que parece ser decisivo na revalorização dos ruídos atualmente seria um discurso supostamente científico por trás da maioria das propostas sonoras ofertadas pelo MERSBE. Em quase todas as mensagens promocionais, encontra-se uma alegação de comprovação científica que garantiria a eficácia do produto. Da ovelhinha Sleep Sheep, cujo anúncio na página da Amazon descreve que o produto foi "cientificamente provado na promoção de um sono melhor", passando por empresas que vendem trilhas sonoras para a alteração das ondas cerebrais, como a Binaural Beats Meditation, a Transparent Corp. ou a IDoser, os sites trazem mensagens fazendo alusão a estudos - frequentemente ao artigo de Oster - e pesquisas científicas que garantem a eficácia dos seus produtos .

A chancela científica, ou pseudocientífica, parece funcionar como um eficiente elemento de aproximação entre ruídos e um público que se permitiria, agora, em nome da conquista de um bem-estar, a fruição de um material sônico, outrora abjeto, incômodo e indesejado. Tal qual na modernidade, uma lógica racionalista e cientificista parece se impor, garantindo que as experiências de escuta com material ruidoso não seriam prejudiciais à saúde, ao contrário, poderiam melhorá-la e garantiriam o bem-estar.

Independentemente do caráter de comprovação realmente científica das propostas sonoras anunciadas, a estratégia interessa como uma mensagem subjacente que propõe que os processos de escuta ocorreriam em dimensões mais profundas, em instâncias cerebrais, para além do complexo auricular e, ainda, que as experiências dessa escuta deflagrariam efeitos para além do meramente sensório e emocional, alterando dinâmicas e estruturas cérebro-neurais em favor do incremento da qualidade de vida.

\subsection{Ruídos puros}

Uma outra hipótese que se pode aventar na revalorização dos ruídos no panorama aural contemporâneo seria a proposta, algo paradoxal, de "purificação" dos ruídos, para uma escuta menos intensa ou incômoda e, principalmente, eficiente na conquista e manutenção do bem-estar. Tal perspectiva se sustentaria com a ideia de que, por serem digitais, os 
produtos sonoros ruidosos podem ser reprocessados, "purificados" ou "docilizados", tornando-se agradáveis enquanto experiência de escuta.

Haveria uma estratégia subjacente aos discursos que promovem os ruídos e seus efeitos positivos que consiste em afirmar um controle e "assepsia" do caráter agressivo e incômodo dos ruídos através de processos que os transformariam em peças sônicas estéreo e de alta definição. Nessa estratégia, as mensagens promocionais evocam termos e qualidades compatíveis com experiências de escutas "puras", como "alta definição" (HD High Definition) e "som estéreo" (stereo), como formas de suavizar uma experiência de escuta em relação aos ruídos que, historicamente, é considerada como dolorida, incômoda, agressiva e disruptiva (HEGARTY, 2007; NOVAK, 2013).

\subsection{Espaço privado vs. Ruídos}

Outro aspecto interessante a ser explorado e melhor compreendido a partir da emergência do MERSBE seria o acolhimento dos ruídos dentro de espaços privados. Isso é digno de nota, uma vez que se pode observar uma crescente especialização da experiência de escuta, tendo como um dos seus propósitos a elaboração de um "som moderno" experiências de escutas controladas, particularmente em relação aos ambientes privados, para que os sons desejados possam se manifestar de modo cada vez mais claro e ruídos fiquem excluídos ou, ao menos, amenizados em seus efeitos perturbadores (STERNE, 2003).

Os trabalhos de Bull e Les Back (2003) e os de Emily Thompson (2004), assim como os de Simone Pereira de Sá (SÁ, 2010), que cita os dois primeiros ao mapear algumas questões pertinentes ao campo dos Estudos de Som - como parte dos movimentos da pesquisadora para promover o diálogo entre o referido campo e a Comunicação - tornam-se aqui valiosos. Thompson investiga como construções de casas de espetáculos nos Estados Unidos - o Symphony Hall, inaugurado em 1900, em Boston, para receber concertos de música clássica, e o Radio City Music Hall, em 1932, em Nova York, voltado a apresentações que passavam a usar captações e amplificações sonoras eletrônicas - representavam e ajudavam a moldar o ideal de som da modernidade. Entre outras características desses locais, estava o controle da circulação do material sônico nos recintos, assim como dos ruídos, garantindo um som "limpo" e "eficiente" - "eficiência medida por sua clareza na forma de sinal 'limpo', sem reverberações, ou qualquer outra marca do ambiente" (SÁ, 2010). 
Com a emergência do MERSBE, há uma problematização da lógica de purificação das ambiências sonoras em espaços privados, uma vez que ruídos podem ser convocados a entrarem em cena para garantir uma boa noite de sono ou um ambiente propício ao estudo, ao trabalho, à meditação. Ainda que se trate, nesse caso, de uma espécie de parede ruidosa que isolaria o ambiente privado de outros ruídos e sons indesejados, trata-se, paradoxalmente, de trazer ruídos para dentro de espaços privados. Tal prática questionaria perspectivas que defendem que classes sociais e culturas com noções mais claras de propriedade privada seriam mais sensíveis aos ruídos, como lembram Bull e Les Back (apud SÁ, 2010) ${ }^{7}$.

Outro aspecto que incide sobre essa mesma questão é a mediação das escutas por fones de ouvidos, prescrição comum para os consumidores do MERSBE, a fim de se atingir plenamente os efeitos de bem-estar aos quais seus produtos se destinam.

Descendendo de práticas da modernidade, quando uma série de propostas de escutas mediadas por tecnologias emergiram, incluindo a escuta binaural com o Teatrofone (Théâtrophone) - que como o nome sugere, propunha a transmissão de peças teatrais e óperas através de fones de ouvido - ou da própria escuta de rádio (STERNE, 2003), os fones de ouvidos estimulam a produção de um espaço de escuta individualizado e privado, ainda que em meio a locais mais amplos, públicos ou não, como o ambiente de trabalho, um ambiente universitário ou mesmo uma residência.

Os fones de ouvidos, dentro dos usos prescritos pelo MERSBE, reforçariam a proposta de uma escuta privada mas que, ao invés de excluir, incluiria ruídos. Assim, mais uma vez, haveria a problematização da lógica de escuta moderna, que conjugava espaços privados com escuta de sons limpos e não ruidosos. Com os produtos MERSBE, a contemporaneidade parece conciliar privatização dos espaços e autonomização das experiências de escuta e ruídos como uma das características da sua cultura aural.

\subsection{Escuta cerebral}

Outro ponto que se quer destacar a partir da emergência do MERSBE é o que se pode entender como um deslocamento da experiência de escuta, teorizada e idealizada desde a modernidade como ocorrendo em um ouvido ideal, "timpânico" (STERNE, 2003), para uma

${ }^{7}$ BULL, M.; BACK, L. (orgs.). The auditory culture reader. Oxford and New York: Berg. Pub, 2003. Apud Sá (2010). 
experiência que residiria no cérebro. Este aspecto parece concentrar todos os anteriores, no que se refere a uma possível modulação da experiência da escuta na contemporaneidade.

A concepção de uma "escuta cerebral" é sugerida em praticamente todas as propostas dos produtos sonoros do MERSBE, seja no caso dos "ruídos coloridos", das batidas binaurais e sons isocrônicos, nas experiências de ASMR ou nas drogas digitais/sonoras. Trata-se de proposições que, apoiadas em supostas comprovações científicas, evidenciam que todo o processo de escuta deve ser compreendido como ocorrendo, efetivamente, no cérebro e, assim, a ideia de uma escuta auricular seria uma espécie de alucinação auditiva. Essa ideia é sintetizada com a proposta das batidas binaurais que, tal como exposto acima, afirma que o som produzido a partir do encontro de dois sons de frequências próximas apresentados separadamente, um a cada ouvido, resultaria em uma escuta de um som que teria como frequência a diferença das frequências dos sons apresentados aos ouvidos. Ou seja, a escuta que prevaleceria não é a dos dois sons nos ouvidos, alucinatória, mas aquela que emerge como resultado final do tratamento dos sons feito pelo cérebro.

Independentemente do fato de toda experiência sensorial contar, efetivamente, com dinâmicas e processos cerebrais, o que está em jogo aqui é a produção de um ideal de experiência de escuta que, mais do que promover um deslocamento da escuta do ouvido para o cérebro, restringe-a a uma única região corpórea ou órgão.

Como aponta Sterne, a construção do ouvido como o órgão autônomo da escuta se deu na virada do século XIX para o XX e essa concepção se manteve por longo período, até que estudos de psicoacústica problematizassem essa ideia, incluindo um complexo de regiões e dinâmicas corporais na experiência da audição.

[...] o canal do ouvido não é o único lugar (no corpo) que conduz vibrações para o nervo auditivo: a cabeça toda pode e, de fato, conduz vibração, assim como a cavidade peitoral [...]. A mandíbula, em particular, é uma útil condutora de som [...] Então, o que nós temos aqui é um corpo psicoacústico, um corpo que adensa as vibrações com o objetivo de transformá-las em som. Som é um produto da percepção, não uma coisa 'externa' - a única coisa 'externa' é a vibração, que o corpo organiza e estratifica no que chamamos de som (STERNE, 2010).

As mensagens que promovem os produtos sonoros do MERSBE não apenas defendem o protagonismo do cérebro como o grande regente dos processos de escuta como apontam-no como sede onde se realizam as operações cognitivas e sensoriais necessárias para o bem-estar: memória, atenção, concentração, aprendizagem e até mesmo orgasmos, 
como anunciam os adeptos do ASMR. Assim, todas as experiências de escuta relacionadas aos diferentes produtos citados - as batidas binaurais usadas na regulação das ondas cerebrais e pelas drogas digitais, a experiência de escuta em profundidade, tridimensional, no caso das peças sonoras que emulam a escuta humana fidedignamente, como o caso Virtual Barber Shop, seriam garantidas pelo protagonismo do cérebro nas dinâmicas de audição e destinadas a ele. É possível que tais ideias sejam reflexos dos discursos (pseudo?) científicos que querem legitimar os produtos MERSBE. Discursos que, por sua vez, refletem outros campos de conhecimento que se debruçam sobre experiências de escuta, como a neurologia da audição, por exemplo.

\section{Considerações finais}

A audição, assim como os demais sentidos, é devedora de processos de evolução da espécie, que define um espectro sonoro para o humano em torno de 20 a $20.000 \mathrm{~Hz}$. Contudo, as experiências sensórias encontram a cultura, capaz de promover recortes ou modulações naquilo que seria uma hipotética e ilusória experiência de "puro sentido" para a espécie. Ou seja, do encontro entre as determinações etológicas e a cultura formam-se as audibilidades, que são as experiências de escuta, processo híbrido entre o biológico e simbólico. Isso valeria para as visualidades, em relação às experiências da visão, as tatilidades, no que diz respeito às experiências táteis e etc. (PEREIRA, 2006).

Nesse sentido, é bastante razoável a hipótese que aventa que as escutas, assim como outras experiências sensórias, são processos construídos a partir de uma complexa relação entre dinâmicas culturais e uma base comum, corpórea e biológica, inata. 0 nó górdio da questão seria compreender como ocorreriam as dinâmicas e jogos entre cultura e base material biológica, singular e específica, que participa do que se compreende como sentidos humanos. Ou seja, compreender minimante quais dinâmicas se inscrevem como jogos simbólicos, relativamente flexíveis, sensíveis a movimentos dentro da própria cultura, e quais se devem mais diretamente à biologia da espécie e às materialidades dos corpos - dos objetos implicados em qualquer processo de escuta, da acústica do ambiente no qual se dá a experiência aural, dos corpos humanos (o conjunto auditivo, as redes neurais, a massa corpórea etc.).

O preâmbulo acima se faz necessário para esclarecer que a pesquisa que investiga o campo sônico nomeado como MERSBE procura considerar diferentes dinâmicas implicadas nos processos de uma possível modulação da escuta de ruídos na contemporaneidade - 
dinâmicas simbólicas e materiais - sem estabelecer uma rígida separação entre esses dois grupos, apostando que tal fronteira seria impossível de ser erigida e, ainda, pouco rentável para o empreendimento investigativo que se propõe.

Os primeiros movimentos de uma pesquisa maior foram apresentados com o presente artigo, cujo primeiro e principal objetivo foi descrever um novo mercado sônico que emerge na contemporaneidade, o MERSBE, a fim de conhecê-lo em pormenores. Ele traz ainda mais complexidade à cultura aural contemporânea e que pode ser sintetizado nos seguintes pontos:

a) trata-se de um mercado cujos produtos são materiais sônicos, constituído de ruídos, de sons e, em algumas manifestações, como no caso dos sons binaurais, de músicas, cujas propostas não estão voltadas para o entretenimento, necessariamente, mas prioritariamente para o bem-estar;

b) tais produtos estão, em geral, disponíveis online e podem ser adquiridos através de compra ou de aquisição gratuita em sites diversos. Ou seja, a maioria dos produtos apresenta-se em formatos digitais, passíveis de download. As exceções são aqueles produtos atrelados a algum objeto, que pode ser um dispositivo eletrônico - como no caso dos pequenos aparelhos produtores de ruído branco e seus congêneres (ruídos rosa e marrom), ou artefatos para ninar bebês, como os bichinhos de pelúcia como a ovelha Sleep Sheep e seus congêneres;

c) por trás de quase todos os produtos oferecidos pelo MERSBE, encontra-se um discurso que quer se sustentar nas ciências, particularmente nas ciências da mente e em diversas disciplinas que se relacionam ao campo biomédico e auditivo, tais como a bioacústica, a neuroaudiologia, a medicina psicoacústica, entre outras;

d) por fim, os números que envolvem o MERSBE são ainda desconhecidos. Contudo, buscas pontuais em sites de compartilhamento de vídeos - como o YouTube - de termos mencionados neste texto permitem que se entreveja dados parciais que sugerem um mercado colossal. Por exemplo, uma busca no YouTube para os termos white noise e binaural, realizada no dia 15 de janeiro de 2019, oferecia cerca de 9,2 milhões e 4,7 milhões de resultados, respectivamente. Para o termo ASMR, uma busca realizada no mesmo dia, oferecia cerca de 11,6 milhões de resultados. Apostase, assim, que esse é um mercado vastíssimo, disperso por toda a internet. 
Basicamente, a proposta da pesquisa se constrói em torno da ideia de explorar perspectivas centradas nos Estudos de Som (STERNE, 2003, 2010; BULL; LES BACK, 2003; SCHAFER, 2001; DE NORA, 2000; SÁ, 2010;), buscando um diálogo com campos de estudos das materialidades (MCLUHAN, 2001; GUMBRECHT, 2004; PEREIRA, 2006; BOIVIN, 2009) e correlatos, como a neurofenomenologia (VARELA, 1996), a biomúsica (BAPTISTA; GRAY, KRAUSE et al.; 2001), a neurociência da audição (KRAUS; WHITE-SCHWOCH, 2017; KRAUS; NICOL, 2017), entre outros. Esse é um movimento investigativo ainda em processo e que se desdobra em estudos futuros. Como norte para tais estudos, uma série de questões se desenha, conforme proposto a seguir.

(1) Seria possível enquadrar o conjunto sônico mobilizado pelo MERSBE como parte relevante das experiências de escuta na contemporaneidade e, assim, incorporá-lo à paisagem sonora hodierna (SCHAFER, 2001)?

(2) Por outro lado, considerando algumas das características desse mercado como o fato de se apresentar, basicamente, no ciberespaço, acessível a partir de tecnologias midiáticas - valeria repensar o próprio conceito de paisagem sonora?

(3) Ainda, poderia o mesmo conjunto sônico ser incorporado como parte da estratégia de afinação do mundo - proposta por Schafer (2001) - à medida em que se apresenta como prescrições auditivas vinculadas à promoção e manutenção do bem-estar?

(4) Quais os principais atores, contextos e materialidades implicados nas modulações das experiências de escuta de ruídos na contemporaneidade? E, ainda, envolvidos na emergência de um mercado como o MERSBE?

(5) Quais os principais modos pelos quais o conjunto sonoro do MERSBE é apropriado no cotidiano, modulando subjetividades, corpos e psiquismo (incluindo aqui a ideia de self), tal como se dá com apropriações da música investigadas por Tia De Nora (DE NORA, 2000)?

Este artigo, obviamente, não teve a pretensão de responder às questões acima formuladas, mas se aproximar delas. Tais questões, assim como outras que surgirem, funcionam como feixes temáticos que orientam o percurso investigativo em processo. Ainda, as questões não têm a intenção de exaurir o debate sobre o MERSBE, pelo contrário, buscam introduzi-lo para que outras perguntas e estudos possam ser formulados e, deste modo, se possa compreender melhor a complexa e ruidosa cultura aural contemporânea. 


\section{Referências}

ARISTÓTELES. Ética a Nicômaco. Lisboa: Martin Claret, 2013.

BAPTISTA, L.GRAY, P. M., KRAUSE, B. et al. The Music of Nature and the Nature of Music. Science. v. 291, n. 5501, p. 52-54, 2001.

BIANCHI, E.P.; SCALABRIN, A.C.; PENTERICH, E. Uma análise do bem-estar psicológico das pessoas nos ambientes organizacionais: Reflexões para a gestão da qualidade de vida no trabalho. RACRE - Revista de Administração, Espírito Santo do Pinhal, v. 6, n. 10, p.93105, jan/dez. 2006.

BOIVIN, N. Material cultures, material minds: the impact of things on human thought, society and evolution. Cambridge: Cambridge Univ. Press, 2009.

BULL, M.; BACK, L. (orgs.). The auditory culture reader. Oxford: Berg. Pub, 2003.

DE NORA, T. Music in everyday life. Massachussets: Cambridge Univ. Press, 2000.

FORD, S. Wreckers of civilisation: the story of coum transmissions \& throbbing gristle. London: Black Dog Publishing, 1999.

GUMBRECHT, H.U. Production of Presence: what meaning cannot convey. Stanford: Stanford Univ. Press, 2004.

HEGARTY, P. Noise/Music: a history. London: Continuum, 2007.

KRAUS, N.; NICOL, T. The power of sound for brain health. Nature human behaviour, [s.l.], v. 1 , n. 10, p. 700, 2017.

KRAUS, N.; WHITE-SCHWOCH, T. Neurobiology of everyday communication: What have we learned from music?. The Neuroscientist, [s.l.], v. 23, n. 3, p. 287-298, 2017.

MCLUHAN, M. Os meios de comunicação como extensões do homem. São Paulo: Cultrix, 2001.

NOVAK, D. JAPANOISE - Music at the edge of circulation. Durham and London: Duke Univ. Press, 2013.

OSTER, G. Auditory beats in the brain. Scientific American, [s.l.], v. 229, n. 4, p. 94-103, 1973.

PEREIRA, V.A. Reflexões sobre as materialidades dos meios: embodiment, afetividade e sensorialidade nas dinâmicas de comunicação das novas mídias. Revista Fronteiras:

Estudos Midiáticos, São Leopoldo, v.8, n.3, p.93-101, set-dez, 2006. 
PEREIRA, V.A.; CASTANHEIRA, J.C.; SARPA, R., Simbiotecnoises: ruídos extremos na cultura do entretenimento. In: SÁ, S.P. de, (org.) Rumos da Cultura da Música - Negócios, Estéticas, Linguagens e Audibilidades. Porto Alegre: Sulina, 2010.

RUSSOLO, L. L'Arte dei rumore. [Itália]: Stampa Alternativa Ed., 2009.

SÁ, S.P. de. A trilha sonora de uma historia silenciosa: som, música, audibilidades e tecnologias na perspectiva dos Estudos de Som. In: SÁ, S.P. de, (org.) Rumos da Cultura da Música - Negócios, Estéticas, Linguagens e Audibilidades. Porto Alegre: Sulina, 2010.

SCHAFER, R.M. A Afinação do Mundo. São Paulo: UNESP, 2001.

SCORSOLINI-COMIN, F.; SANTOS, M.A. O estudo científico da felicidade e a promoção da saúde: revisão integrativa da literatura. Revista Latino-Americana de Enfermagem. Ribeirão Preto, v. 18, n.3, p.188-195, mai-jun/2010.

STERNE, J. 0 mp3 como um artefato cultural. In: SÁ, S.P. de (org.) Rumos da Cultura da Música - Negócios, Estéticas, Linguagens e Audibilidades. Porto Alegre: Sulina, 2010.

STERNE, J. The audible past: cultural origins of sound reproduction. Durham and London: Duke University Press, 2003.

THOMPSON, E. The Soundscape of Modernity: Architectural Acoustics and the Culture of Listening in America, 1900-1933. Cambridge: Mit Press, 2004.

VARELA, F. J. Neurophenomenology: A methodological remedy for the hard problem. Journal of Consciousness Studies, [s.l.], v. 3, n. 4, p. 330-349, 1996.

\section{MERSBE - noise and sound market for well- \\ being: hearing modulations and contemporary aural cultur}

\section{abstract}

This article explores a unique sound market: the MERSBE - an acronym in Portuguese for "Noise and Sound Market for WellBeing". This market is characterized by presenting noisy proposals for different purposes, such as improving memory and sleep quality, increasing the ability to concentrate, physical and psychological cures, among others, always committed to wellbeing. The emergence of MERSBE also reveals how contemporary culture establishes new ways of relating to noise, inverting what seemed to be the logic of its uses until recently. From a provocative and challenging position - as in the case of Russolo's Futurist Manifesto, in concrete music's movement, or even in musicians like E. Varese and J. Cage, up to the punk and Japanese noise - the noises now seem to serve the global markets, being welcomed and cultivated as positive and docile experiences. How can this affect contemporary aural culture? That's the central question of this article, which was elaborated 
from an immersion in social networking sites, such as Youtube, for the observation of the analyzed sonic products. The main theoretical reference is the Sound Studies and authors who work with research around materialities of communication, mainly. As final results, the article points out some factors that can already be interviewed as relevant participants, in the modulation of noise listening in contemporary aural culture.

\section{Keywords}

MERSBE. Noise. Well-Being. Aural Culture.

\section{Autoria para correspondência}

Vinícius Andrade Pereira

vinianp@gmail.com

\section{Como citar}

PEREIRA, Vinícius Andrade. MERSBE - mercado de ruídos e sons para o bem estar: modulações da escuta e cultura aural contemporânea.. Intexto, Porto Alegre, n. 52, e-98204, jan./dez. 2021.

DOI: https://doi.org/10.19132/1807-8583202152.98204

Recebido em 13/11/2019

Aceito em 30/12/2019 